\title{
Role of scavenger receptor A and CD36 in diet- induced nonalcoholic steatohepatitis in hyperlipidemic mice
}

Citation for published version (APA):

Bieghs, V., Wouters, K., van Gorp, P. J., Gijbels, M. J. J., de Winther, M. P. J., Binder, C. J., Lutjohann, D., Febbraio, M., Moore, K. J., van Bilsen, M., Hofker, M. H., \& Shiri-Sverdlov, R. (2010). Role of scavenger receptor A and CD36 in diet-induced nonalcoholic steatohepatitis in hyperlipidemic mice. Gastroenterology, 138(7), 2477-2486. https://doi.org/10.1053/j.gastro.2010.02.051

Document status and date:

Published: 01/06/2010

DOI:

10.1053/j.gastro.2010.02.051

Document Version:

Publisher's PDF, also known as Version of record

Document license:

Taverne

Please check the document version of this publication:

- A submitted manuscript is the version of the article upon submission and before peer-review. There can be important differences between the submitted version and the official published version of record.

People interested in the research are advised to contact the author for the final version of the publication, or visit the DOI to the publisher's website.

- The final author version and the galley proof are versions of the publication after peer review.

- The final published version features the final layout of the paper including the volume, issue and page numbers.

Link to publication

\footnotetext{
General rights rights.

- You may freely distribute the URL identifying the publication in the public portal. please follow below link for the End User Agreement:

www.umlib.nl/taverne-license

Take down policy

If you believe that this document breaches copyright please contact us at:

repository@maastrichtuniversity.nl

providing details and we will investigate your claim.
}

Copyright and moral rights for the publications made accessible in the public portal are retained by the authors and/or other copyright owners and it is a condition of accessing publications that users recognise and abide by the legal requirements associated with these

- Users may download and print one copy of any publication from the public portal for the purpose of private study or research.

- You may not further distribute the material or use it for any profit-making activity or commercial gain

If the publication is distributed under the terms of Article $25 \mathrm{fa}$ of the Dutch Copyright Act, indicated by the "Taverne" license above, 


\title{
BASIC-LIVER, PANCREAS, AND BILIARY TRACT
}

\section{Role of Scavenger Receptor A and CD36 in Diet-Induced Nonalcoholic Steatohepatitis in Hyperlipidemic Mice}

\author{
VEERLE BIEGHS, * KRISTIAAN WOUTERS, * PATRICK J. VAN GORP, * MARION J. J. GIJBELS, \\ MENNO P. J. DE WINTHER, ${ }^{*}$ CHRISTOPH J. BINDER, ${ }^{\ddagger}, \S$ DIETER LÜTJOHANN," MARIA FEBBRAIO," \\ KATHRYN J. MOORE," MARC VAN BILSEN, ${ }^{*}$ MARTEN H. HOFKER, ${ }^{* *}$ and RONIT SHIRI-SVERDLOV*
}

*Department of Molecular Genetics, Pathology and Physiology, Nutrition and Toxicology Research (NUTRIM) and Cardiovascular Research (CARIM) Institutes of Maastricht, University of Maastricht, Maastricht, The Netherlands; ${ }^{\ddagger}$ Center for Molecular Medicine, Austrian Academy of Sciences, and ${ }^{\circledR}$ Department of Medical and Chemical Laboratory Diagnostics, Medical University of Vienna, Vienna, Austria; "Institute of Clinical Chemistry and Pharmacology, University of Bonn, Bonn, Germany; "Department of Cell Biology, Lerner Research Institute, Cleveland, Ohio; "Leon H. Charney Division of Cardiology, New York University Medical Center, New York, New York; and **Department of Pathology \& Laboratory Medicine, University Medical Center Groningen, University of Groningen, The Netherlands

BACKGROUND \& AIMS: Nonalcoholic steatohepatitis $(\mathrm{NASH})$ is a disorder that consists of steatosis and hepatic inflammation. It is not known why only some people with steatosis develop NASH. Recently, we identified dietary cholesterol as a factor that directly leads to hepatic inflammation and hepatic foam cell formation. We propose a mechanism by which Kupffer cells (KCs) take up modified cholesterol-rich lipoproteins via scavenger receptors (SRs). KCs thereby accumulate cholesterol, become activated, and may then trigger an inflammatory reaction. Scavenging of modified lipoproteins mainly depends on CD36 and macrophage scavenger receptor 1 . METHODS: To evaluate the involvement of SR-mediated uptake of modified lipoproteins by KCs in the development of diet-induced NASH, female low-density lipoprotein receptor-deficient $\left(\mathrm{Ldlr}^{-/}\right)$ mice were lethally irradiated and transplanted with bone marrow from $\mathrm{Msr}^{+/+} / \mathrm{Cd} 36^{+/+}$or $\mathrm{Msr} 1^{-/-} / \mathrm{Cd} 36^{-/-}$mice and fed a Western diet. RESULTS: Macrophage and neutrophil infiltration revealed that hepatic inflammation was substantially reduced by approximately 30\% in $\mathrm{Msr1}^{-/-}$/ Cd36 $6^{-/-}$-transplanted mice compared with control mice. Consistent with this, the expression levels of well-known inflammatory mediators were reduced. Apoptotis and fibrosis were less pronounced in $M s r 1^{-/-} / \mathrm{Cd}_{3} 6^{-/-}$-transplanted mice, in addition to the protective phenotype of natural antibodies against oxidized low-density lipoprotein in the plasma. Surprisingly, the effect on hepatic inflammation was independent of foam cell formation. CONCLUSIONS: Targeted inactivation of SR pathways reduces the hepatic inflammation and tissue destruction associated with NASH, independent of hepatic foam cell formation.

Keywords: Fatty Liver; Inflammation; Scavenger Receptors; Kupffer Cells.
Tonalcoholic steatohepatitis (NASH) is considered 1 to be the hepatic event of the metabolic syndrome. It is characterized by hepatic lipid accumulation (steatosis) combined with inflammation. Estimates of the general United States population indicate that approximately $2 \%-3 \%$ of all adults have NASH and that this prevalence is expected to rise rapidly because of the increasing prevalence of obesity. ${ }^{1}$ The current view on the pathogenesis of diet-induced liver inflammation is that hepatic steatosis is a critical prerequisite for the development of inflammation. Whereas steatosis itself is generally considered benign and reversible, the presence of inflammation can lead to further progression of NASH, resulting in liver fibrosis, cirrhosis, and, eventually, liver failure and hepatocellular carcinoma. ${ }^{2}$ Thus, the progression toward hepatic inflammation represents a key step in NASH development. It is not yet known why only a small percentage of people with steatosis develop NASH. Although several processes have been identified that par-

\footnotetext{
Abbreviations used in this paper: $\mathrm{ABC}$, adenosine triphosphate binding cassette; acLDL, acetylated LDL; ALT, alanine aminotransferase; AST, aspartate aminotransferase; APOE, apolipoprotein E; BCA, bicinchoninic acid; Col1 $\alpha 1$, collagen type $1 \alpha 1$; cDNA, complementary DNA; Cu-OxLDL, copper oxidized LDL; FFA, free fatty acid; HFC, high-fat, high-cholesterol; Ig, immunoglobulin; KC, Kupffer cell; LDL, low-density lipoprotein; MDA, malondialdehyde; MMP, matrix metalloprotease; MPO, myeloperoxidase; MSR, macrophage scavenger receptor; NASH, nonalcoholic steatohepatitis; NF- $\kappa$ B, nuclear factor $\kappa$-B; NIMP, nogointeracting-mitochondrial protein; $\mathrm{ORO}$, oil red $\mathrm{O}$ staining; oxLDL, oxidized LDL; PPAR, peroxisome proliferator activated receptor; SR, scavenger receptors; TC, total cholesterol; TG, triglycerides; TGF- $\beta$, transforming growth factor $\beta$; TIMP, tissue inhibitor of metalloproteinase; TLR, toll-like receptor; TNF, tumor necrosis factor; tp, transplanted.

(c) 2010 by the AGA Institute $0016-5085 / \$ 36.00$ doi:10.1053/j.gastro.2010.02.051
} 
ticipate in the development of hepatic inflammation, ${ }^{3-7}$ the actual trigger for the inflammatory response remains uncertain.

We and other researchers have recently shown that dietary cholesterol is an important risk factor for the development of hepatic inflammation. ${ }^{8-10}$ Interestingly, hyperlipidemic mice fed a high-fat, high-cholesterol (HFC) diet develop early hepatic inflammation, which is associated with bloated Kupffer cells (KC), resembling foam cells in atherosclerosis. These KCs with a foamy appearance have also been identified in other studies in the sinusoidal space of the liver. ${ }^{11,12}$ Strikingly, omitting cholesterol from the diet in these mice resulted in a dramatic inhibition of hepatic inflammation and foam cell formation. ${ }^{8}$ An attractive hypothesis is that, because of the decreased lipoprotein uptake by hepatocytes in hyperlipidemic mice, lipoproteins have a longer residence time in the plasma and are therefore more prone to be modified and subsequently scavenged by KCs. This process ultimately results in $\mathrm{KC}$ activation, which may be responsible for triggering the hepatic inflammation and KC cholesterol accumulation.

Like typical macrophages, KCs express scavenger receptors $(\mathrm{SRs})^{13}$ and are thus capable of taking up modified lipoproteins. In vitro, foam cell formation has been shown to depend mainly on 2 different SRs: SR-A (macrophage scavenger receptor 1 [MSR1]) and CD36. ${ }^{14}$ MSR1 was found to account for the majority (80\%) of macrophage uptake of acetylated low-density lipoprotein (LDL) (acLDL) but has a lower affinity for oxidized LDL (oxLDL). ${ }^{14,15}$ CD36 binds moderately oxLDL, rather than acLDL, ${ }^{16}$ and was found necessary for oxLDL-induced c-Jun-N-terminal kinase activation. ${ }^{17}$ Despite numerous studies addressing the role of these 2 SRs in atherosclerosis, their roles remain uncertain. Whereas clear effects of MSR1 and CD36 on cholesterol uptake and foam cell formation have been found in vitro, ${ }^{14}$ the results in vivo are less consistent. Findings in mouse models of atherosclerosis lacking one or both of these SRs have ranged from reduced foam cell formation and atherosclerosis to no effect or to greater foam cell formation and increased atherosclerosis. ${ }^{16,18,19}$ Whereas the reasons for these discrepancies are unclear, there is a growing appreciation of the numerous functions that SRs can play in addition to lipoprotein uptake, including their roles in inflammatory signal transduction and tissue homeostasis.

To investigate the contribution of Msr1 and Cd36 expression by macrophages on hepatic modified lipoprotein uptake and inflammation, we performed a bone marrow transplantation of donor bone marrow from mice with targeted deletions for $M s r 1$ and $C d 36$ into lethally irradiated low-density lipoprotein receptor-deficient $\left(L d l r^{-/-}\right)$recipient mice. We hypothesized that $M s r 1^{-/-} / C d 36^{-/-}$-transplanted (-tp) mice on a high-fat diet would develop reduced levels of hepatic inflammation compared with mice with normal hematopoietic cells because of a decreased uptake of modified lipoproteins by KCs. Surprisingly, whereas deletion of Msr1 and Cd36 in hematopoietic cells failed to block cholesterol accumulation in KCs, these transplanted mice showed reduced markers for NASH, including less inflammation, apoptosis, and fibrosis after high-fat feeding. These data suggest that SR expression by KCs in the liver increases the risk for NASH in the presence of high levels of plasma-modified lipoproteins.

\section{Materials and Methods}

\section{Experimental Setup}

Female $\mathrm{Ldlr}^{-/-}$mice were lethally irradiated and transplanted with $\mathrm{Msr}^{+/+} / \mathrm{Cd} 36^{+/+}$and $\mathrm{Msr}^{-/-} / \mathrm{Cd} 36^{-/-}$ bone marrow. After a recovery period of 9 weeks, the mice were given an HFC diet for 7 days $\left(\mathrm{n}=8\right.$ in both $\mathrm{Msr}^{+/+} /$ $\mathrm{Cd} 36^{+/+}$-tp and $\mathrm{Msr1} 1^{-/-} / \mathrm{Cd} 36^{-/-}$-tp mice) and 3 months ( $\mathrm{n}=7$ in $\mathrm{Msr}^{+/+} / \mathrm{Cd} 36^{+/+}$-tp group, $\mathrm{n}=8$ in $M s r^{-/-} / C d 36^{-/-}$-tp group). Chow fed mice, killed after 9 weeks' recovery, were used as the control group ( $\mathrm{n}=7$ in both $\mathrm{Msr}^{+/+} / \mathrm{Cd} 36^{+/+}$-tp and $\mathrm{Msr} 1^{-/-} / \mathrm{Cd} 36^{-/-}$-tp mice).

Collection of blood, specimens, lipid analysis in plasma and liver, liver histology, RNA isolation, complementary DNA (cDNA) synthesis and qualitative polymerase chain reaction, determination of chimerism, aminotransferases, oxysterols, and autoantibody titers against modified LDL are described extensively in Supplementary Materials and Methods.

\section{Statistical Analysis}

Data were statistically analyzed by performing 2-tailed nonpaired $t$ tests for comparing $\mathrm{Msr}^{+/+} / \mathrm{Cd}_{3} 6^{+/+}$-tp and $\mathrm{Msr}^{-/-} / \mathrm{Cd} 36^{-/-}$-tp mice for each diet group. Oneway analysis of variance test was used for comparing the different time points of high-fat feeding within the same acceptor mice. Data were expressed as the mean \pm standard error of mean and considered significant at $* P<.05$ $\left({ }^{*} P<.05\right.$, ${ }^{* *} P<.01$, and ${ }^{*}{ }^{*} P<.001$, respectively).

\section{Results \\ Plasma and Liver Lipid Levels in Msr1 ${ }^{+/+} /$ $\mathrm{Cd36}^{+/+}$-and $\mathrm{Msr1}^{-/-} / \mathrm{Cd}^{-1-/-}$ Transplanted Mice}

To establish the role of Msr1 and Cd36 on dietinduced NASH, $\mathrm{Ldll}^{-/-}$mice were transplanted with $\mathrm{Msr}^{1^{+/+}} / \mathrm{Cd} 36^{+/+}$and $\mathrm{Msr}^{-/-} / \mathrm{Cd} 36^{-/-}$bone marrow. Chimerism determination revealed an engraftment efficiency of $99 \%$. After a recovery period of 9 weeks, mice received an HFC diet for either 7 days or 3 months. Chow fed mice that were killed after 9 weeks recovery served as control groups. The body weights were not significantly different between all the groups (Supplementary Figure 1). As expected, HFC feeding increased plasma triglycerides (TG) and total cholesterol (TC) levels in a timedependent manner in both transplanted groups after 

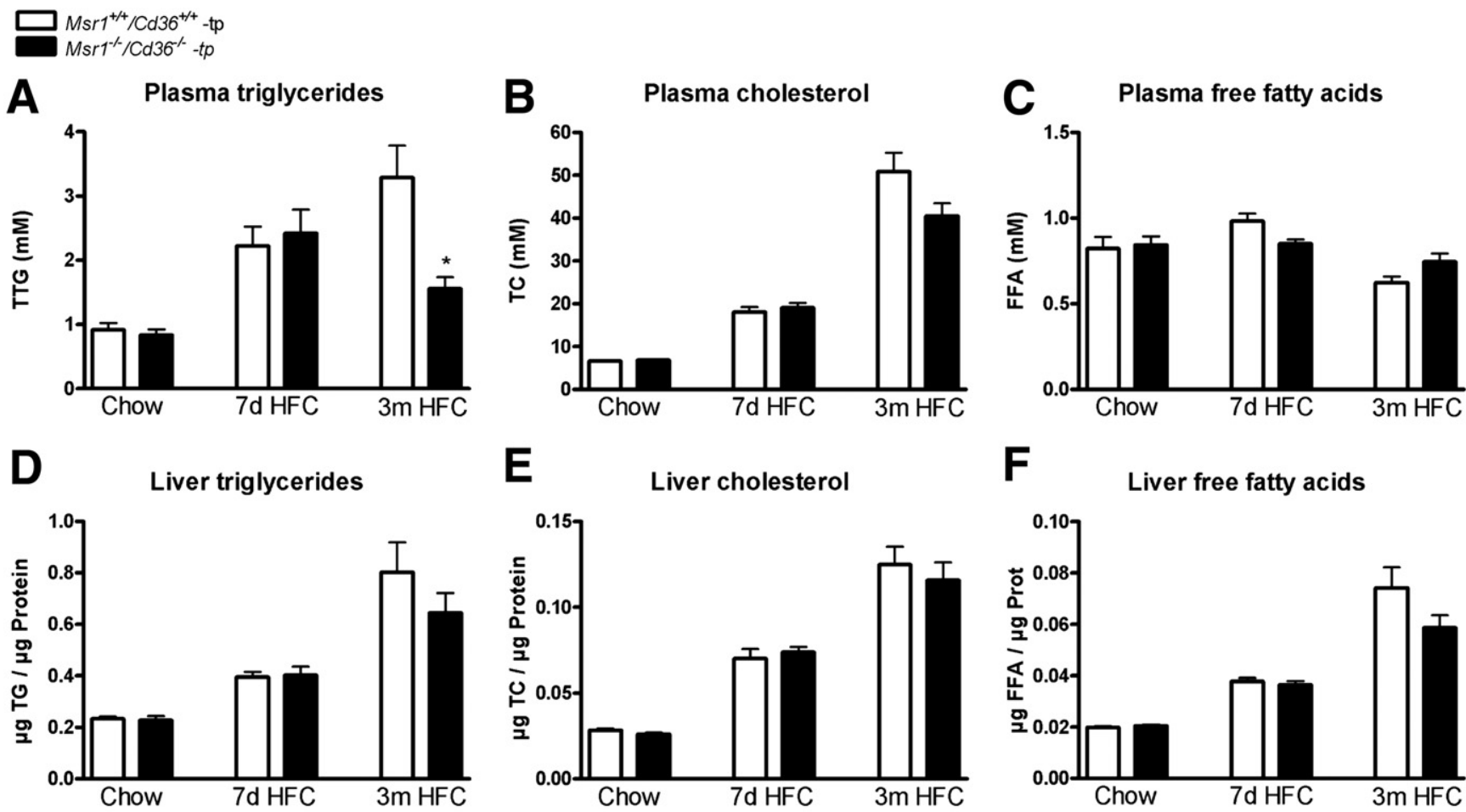

Figure 1. Plasma and liver lipid levels. ( $A-C$ ) Plasma total triglycerides (TG), total cholesterol (TC), and free fatty acids (FFA) after chow, 7 days, and 3 months on an HFC diet. (D-F) Liver TG, TC, and FFA after chow and 7 days and 3 months on an HFC diet. *Significantly different from the age-matched $\mathrm{Msr}^{+/+} / \mathrm{Cd} 36^{+/+}$-tp group.

periods of 7 days and 3 months (Figure $1 A$ and $B$ ) (TG: $P=.0003$ for $M s r 1^{+/+} / C d 36^{+/+}-$tp mice and $P=.0007$ for $M s r 1^{-/-} / C d 36^{-/-}$-tp mice; TC: $P<.0001$ for both $\mathrm{Msr}^{+/+} /$ $\mathrm{Cd} 36^{+/+}$-tp and $\mathrm{Msr} 1^{-/-} / \mathrm{Cd} 36^{-/-}$-tp mice). Surprisingly, $M s r 1^{-/-} / C d 36^{-/-}$-tp mice displayed lower TG levels after 3 months of an HFC diet than $\mathrm{Msr}^{+/ /+} / \mathrm{Cd} 36^{+/+}$-tp mice $(P=.009)$. A similar trend was observed for plasma cholesterol after 3 months of HFC diet; however, this did not reach statistical significance $(P=.08)$. No effect on free fatty acid (FFA) levels was detected (Figure 1C).

Both short- and long-term HFC feeding resulted in the development of equal levels of steatosis in the 2 transplanted groups, with increasing levels after 7 days and 3 months of HFC diet compared with chow fed mice (time effect of TG, TC, and FFA: $P<.0001$ for both $\mathrm{Msr1}^{+/+} /$ $\mathrm{Cd} 36^{+/+}$-tp and $\mathrm{Msr1} \mathrm{1}^{-/-} / \mathrm{Cd} 36^{-/-}$-tp mice). Neither hepatic TG levels nor hepatic TC and FFA differed between the 2 transplanted groups (Figure $1 D-F$ ). Scoring of HEand oil red O-stained liver sections by a trained pathologist confirmed this observation (Supplementary Figures 2 and 3$)$.

\section{Lower Levels of Hepatic Inflammation and Apoptosis in the $\mathrm{Msr}^{-/-} / \mathrm{Cd36}^{-/-}$ Transplanted Mice}

To determine whether combined deletion of Msr 1 and $C d 36$ on bone marrow cells affected the level of hepatic inflammation, liver sections were stained for inflammatory cell markers. For both short- and long-term
HFC feeding, counting of Mac-1-positive cells (infiltrated macrophages and neutrophils) and nogo-interacting-mitochondrial protein (NIMP)-positive cells (specifically neutrophils) revealed that hepatic inflammation was increased compared with chow fed mice $(P<.0001$ for both Mac1 and NIMP in both $M s r 1^{+/+} / C d 36^{+/+}$-tp and $M s r 1^{-/-} / C d 36^{-/-}$-tp mice) but was significantly lower in the $\mathrm{Msr}^{-/-} / \mathrm{Cd} 36^{-/-}$-tp mice compared with $\mathrm{Msr}^{+/+} /$ Cd36 $6^{+/+}$-tp mice (Mac1: $P=.009$ [7 days], $P=.05[3$ months]; Nimp: $P=.02$ [7 days], $P=.007$ [3 months]) (Figure $2 A$ and $B$ ). Moreover, when present, the positive cells were more clustered in the $\mathrm{Msr} 1^{+/+} / \mathrm{Cd} 36^{+/+}$-tp mice (Figure $2 D$ and $E$ ). The number of $\mathrm{CD}^{+}$cells (T cells) was also elevated upon HFC $\operatorname{diet}(P<.0001$ for both $M s r 1^{+/+} / C d 36^{+/+}$-tp and $M s r 1^{-/-} / C d 36^{-/-}$-tp mice), and $M s r 1^{-/-} / C d 36^{-/-}$tp mice showed less positive $\mathrm{T}$ cells after 3 months of HFC diet compared with $\mathrm{Msr}^{+/+} /$ $C d 36^{+/+}$-tp mice $(P=.0008)$ (Figure $2 C$ ).

To define further the differences in inflammation between the 2 groups, we determined the expression of several genes known to be involved in inflammation. Table 1 shows that expression of tumor necrosis factor (Tnf) was significantly lower in the $M s r 1^{-/-} / C d 36^{-/-}$-tp mice after 3 months on an HFC diet compared with $M s r 1^{+/+} / C d 36^{+/+}$-tp mice $(P=.02)$, confirming the histologic data. Despite a trend toward reduced expression of the proinflammatory cytokine interleukin 6 (Il-6), it was not significantly changed. The expression of both 
$\mathrm{Msr1}^{1 /} / \mathrm{Cd} 36^{-1}-\mathrm{tp}$
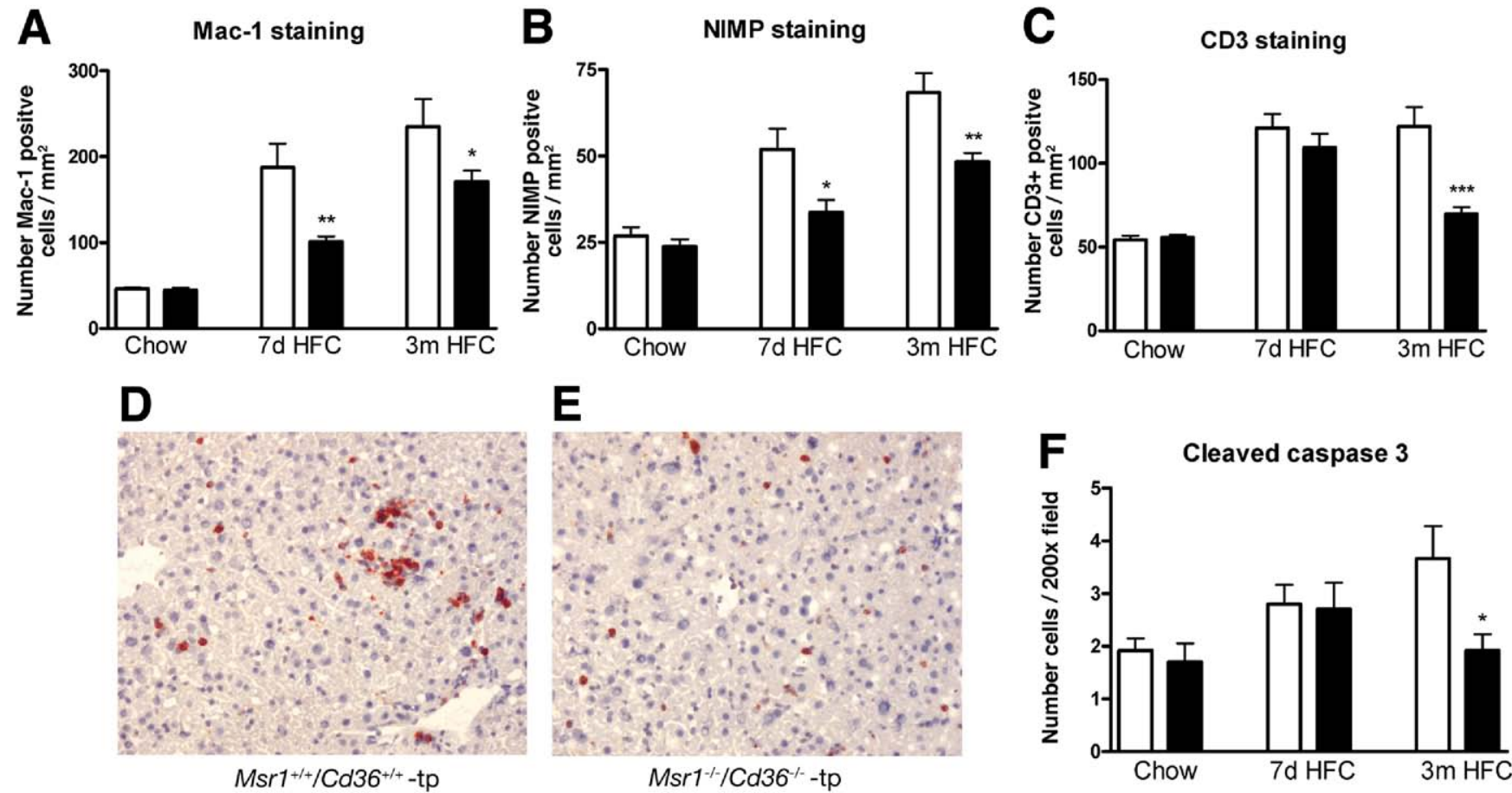

Figure 2. Parameters of hepatic inflammation and apoptosis. (A-C) Liver sections were stained for infiltrated macrophages and neutrophils (Mac-1), neutrophils (NIMP), and T cells $\left(C D 3^{+}\right)$, respectively, and counted. ( $D$ and $E$ ) Representative pictures of Mac-1 staining (original magnification, 200 $\times$ ) after 7 days of HFC feeding in $M s r 1^{+/+} / C d 36^{+/+}$-tp and $M s r 1^{-/-} / C d 36^{-/-}$-tp mice, respectively. (F) Apoptosis was quantified by cleaved caspase 3 staining. ${ }^{*}$ Significantly different from age-matched $M s r 1^{+/+} / C d 36^{+/+}$-tp group. ${ }^{\star} P<.05,{ }^{\star *} P<.01$, and ${ }^{\star \star *} P<.001$, respectively.

toll-like receptors (TLR) 2 and 4 (Tlr-2 and Tlr-4), 2 well-known receptors involved in NASH, was lower in the $M s r 1^{-/-} / C d 36^{-/-}$-tp mice after 7 days on an HFC diet compared with $\mathrm{Msr}^{+/+} / \mathrm{Cd} 36^{+/+}$-tp mice $(P=.03 ; P=$ .004 , respectively), but not after 3 months. Moreover, the expression levels of the anti-inflammatory nuclear receptors peroxisome proliferator activated receptor (Ppar)- $\alpha$ and $-\gamma$ were higher in the $\mathrm{Msr1}^{-/-} / \mathrm{Cd} 36^{-/-}$-tp mice after 3 months of an HFC diet than in mice with $\mathrm{Msr}^{+/+} /$ $C d 36^{+/+}$bone marrow $(P=.001 ; P=.03$, respectively). Together, these data are consistent with a reduction in inflammation in mice lacking hematopoietic expression of CD36 and SR-A.

The death of KCs and hepatocytes by apoptosis is thought to give rise to larger regions of liver damage. To test whether there was a relationship between inflammation and apoptosis in these mice, liver sections were stained for cleaved caspase 3 staining. After 3 months of HFC feeding, a significant decrease in cleaved caspase 3 -positive inflammatory cells and, to a lesser extent, in hepatocytes was observed in livers of $\mathrm{Msr}^{-/-} / \mathrm{Cd}_{3} 6^{-/-}$-tp mice $(P=.04)$ (Figure $2 F)$.

Table 1. Gene Expression Analysis of Inflammatory Related Genes

\begin{tabular}{|c|c|c|c|c|c|c|c|c|c|}
\hline \multirow[b]{2}{*}{ Gene } & \multicolumn{3}{|c|}{ Chow } & \multicolumn{3}{|c|}{7 Days' HFC } & \multicolumn{3}{|c|}{3 Months' HFC } \\
\hline & $\mathrm{Msr1}^{+/+} / \mathrm{CD}^{+/+}$ & $\mathrm{Msr1}^{-/-} / \mathrm{CD} 36^{-/-}$ & $P$ value & $\mathrm{Msr1}^{+/+} / \mathrm{CD}^{+/+}$ & $\mathrm{Msr1}^{-/-} / \mathrm{CD} 36^{-/-}$ & $P$ value & $\mathrm{Msr1}^{+/+} / \mathrm{CD}^{+/+}$ & $\mathrm{Msr1}^{-/-} / \mathrm{CD} 36^{-/-}$ & $P$ value \\
\hline Tnf & $1( \pm 0.12)$ & $1.01( \pm 0.15)$ & .97 & $1.36( \pm 0.29)$ & $0.86( \pm 0.11)$ & .12 & $6.44( \pm 0.97)$ & $3.71( \pm 0.42)$ & $.02 *$ \\
\hline $11-6$ & $1( \pm 0.17)$ & $0.89( \pm 0.13)$ & .61 & $1.80( \pm 0.31)$ & $1.29( \pm 0.19)$ & .17 & $0.49( \pm 0.11)$ & $0.44( \pm 0.08)$ & .10 \\
\hline TIr-2 & $1( \pm 0.10)$ & $0.86( \pm 0.09)$ & .31 & $1.38( \pm 0.24)$ & $0.77( \pm 0.07)$ & $.03 *$ & $2.12( \pm 0.26)$ & $1.95( \pm 0.23)$ & .64 \\
\hline TIr-4 & $1( \pm 0.08)$ & $0.78( \pm 0.05)$ & $.04 *$ & $1.23( \pm 0.08)$ & $0.91( \pm 0.02)$ & $.004 * *$ & $2.30( \pm 0.16)$ & $1.92( \pm 0.02)$ & .07 \\
\hline Ppar- $\alpha$ & $1( \pm 0.07)$ & $0.78( \pm 0.06)$ & .06 & $1.23( \pm 0.06)$ & $1.15( \pm 0.06)$ & .37 & $1.19( \pm 0.06)$ & $1.49( \pm 0.04)$ & $.001 * * *$ \\
\hline Ppar- $\gamma$ & $1( \pm 0.25)$ & $0.99( \pm 0.20)$ & .97 & $3.85( \pm 0.65)$ & $2.58( \pm 0.48)$ & .13 & $11.15( \pm 1.09)$ & $18.97( \pm 1.98)$ & $.007 * *$ \\
\hline
\end{tabular}

NOTE. Gene expression analysis of 4 well-known inflammatory markers: tumor necrosis factor (Tnf), interleukin 6 (II-6), toll-like receptors 2 and 4 (TIr-2 and -4), and 2 anti-inflammatory markers, peroxisome proliferator-activated receptors $\alpha$ and $\gamma($ Ppar- $\alpha$ and $-\gamma)$, respectively. Data were set relative to the $M_{s} 1^{+/+} / C^{\prime} d 36^{+/+}$-tp group on chow diet.

$* P<.05$.

$* * P<.01$.

$* * * P<.001$ 
A

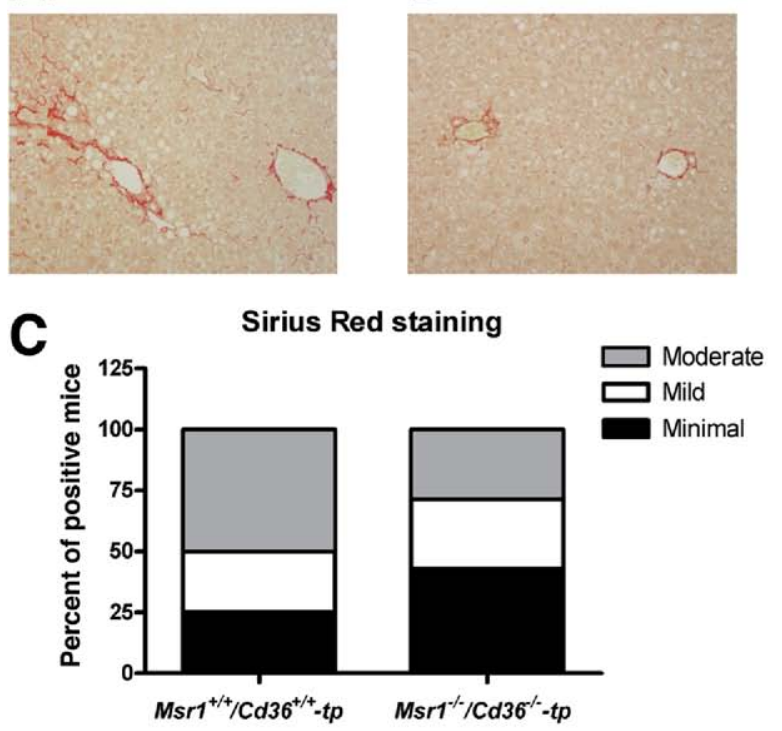

D

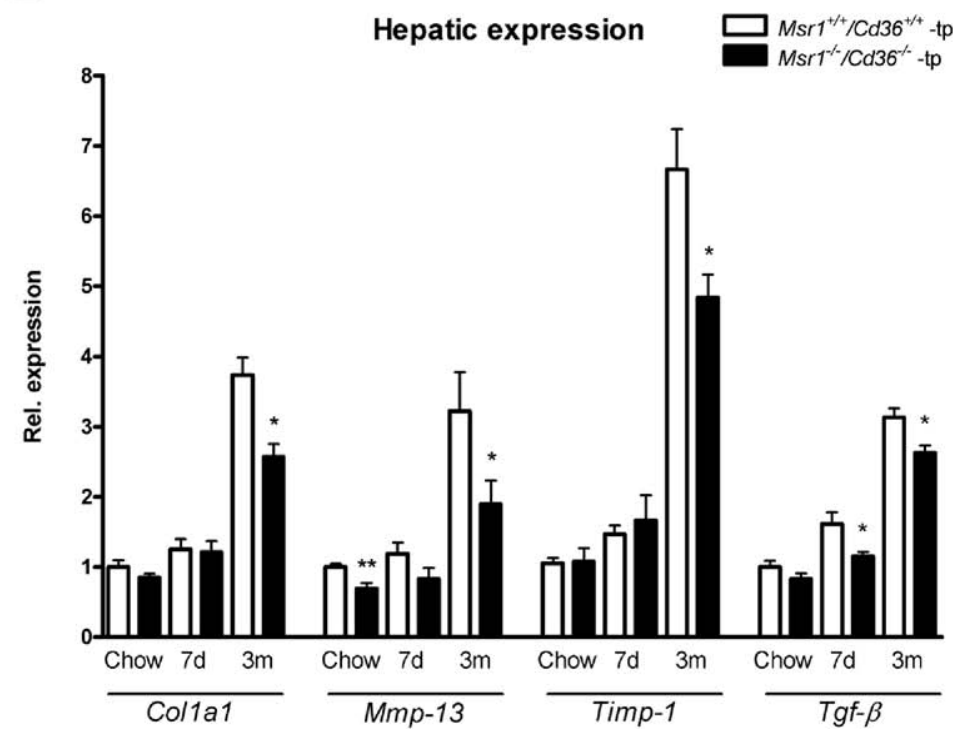

Figure 3. Parameters of hepatic fibrosis. $(A-C)$ Representative pictures (original magnification, $200 \times$ ) of Sirius red-positive sections after 3 months of HFC diet in $\mathrm{Msr}^{+/+} / \mathrm{Cd} 36^{+/+}$-tp $(A)$ and $\mathrm{Msr}^{-/-} / \mathrm{Cd} 36^{-/-}$-tp mice (B). (C) Quantification of Sirius red staining after 3 months of HFC diet. Livers were quantified as minimal, mild, or moderate positive for collagen. (D) Gene expression analysis of Col1 $\alpha 1, \mathrm{Mmp}-13$, Timp-1, and Tgf- $\beta$. Data were set relative to the $\mathrm{Msr} 1^{+/+} / \mathrm{Cd} 36^{+/+}$-tp mice on chow diet. ${ }^{*}$ Significantly different from age-matched $\mathrm{Msr} 1^{+/+} / \mathrm{Cd} 36^{+/+}$-tp group. ${ }^{*} P<.05$ and ${ }^{\star \star} P<.01$, respectively.

The presence of elevated transaminases like alanine aminotransferase (ALT) and aspartate aminotransferase (AST) in plasma is considered to be a sensitive indicator of liver damage. In the present study, the plasma levels of these liver enzyme levels increased with the length of time of HFC feeding (ALT: $P=.0017$ for $\mathrm{Msr}^{+/+} / \mathrm{Cd} 36^{+/+}$-tp mice and $P=.019$ for $M s r 1^{-/-} / C d 36^{-/-}$-tp mice; AST: $P=.024$ for $M s r 1^{+/+} / C d 36^{+/+}$-tp mice and $P=.12$ for $M s r 1^{-/-} / \mathrm{Cd}_{36^{-/-}}$tp mice). However, neither ALT nor AST levels were significantly different between $\mathrm{Msr}^{+/+}$/ $\mathrm{Cd} 36^{+/+}$-tp and $\mathrm{Msr1}^{-/-} / \mathrm{Cd} 36^{-/-}$-tp mice (Supplementary Figure 4).

\section{Hepatic Fibrosis Is Less Pronounced in Msr1-/- $/ \mathrm{Cd36}^{-/-}$Transplanted Mice Compared With Msr1 ${ }^{+/+} / \mathrm{Cd} 6^{+/+}$ Transplanted Mice}

Hepatic fibrosis is viewed as one of the advanced consequences of NASH. After 3 months of HFC diet, $M s r 1^{-/-} / \mathrm{Cd} 6^{-/-}$-tp mice showed less hepatic fibrosis than $\mathrm{Msr}^{+/+} / \mathrm{CD}^{+/+}$-tp mice as evidenced by collagen staining with Sirius red (Figure $3 A-C$ ). Collagen content was lower in livers of $\mathrm{Msr1}^{-1-} / \mathrm{Cd} 36^{-/-}$-tp mice and was primarily localized near vessels of periportal and centrolobular regions. Gene expression of 4 well-known fibrogenic-related genes in liver confirmed the findings of the Sirius red staining. After 3 months of HFC diet, expression levels of these genes were increased compared with chow and 7 days of HFC diet. Comparing $M s r 1^{-/-} /$ Cd36-/- tp mice with $M s r 1^{+/+} / C d 36^{+/+}$-tp mice after 3 months of HFC feeding revealed a significant decrease in fibrosis (ie, collagen type $1 \alpha 1$ [Col1a1] [P=.005], matrix metalloprotease 13 [Mmp-13] [P=.05], tissue inhibitor of metalloproteinase 1 [Timp-1] $[P=.002]$, and transforming growth factor $\beta[\operatorname{Tg} f-\beta][P=.01]$ ) (Figure $3 D$ ).

\section{No Difference in Foamy Appearance of KCs Between the Models}

Despite the absence of the 2 major modified lipoprotein receptors in macrophages, scoring of HEstained (data not shown) and CD68 (macrophage marker that stains KCs)-positive sections did not reveal a reduction in the size or presence of foamy $\mathrm{KCs}$ in $\mathrm{Msr}^{-/-}$/ $C d 36^{-/-}$-tp mice (Figure $4 A-C$ ). Moreover, a fluorescent double staining with CD68 and filipin (cholesterol marker) showed that the cholesterol content inside KCs increased with the size of the KCs upon HFC diet and that there were no differences in cholesterol content between KCs of $\mathrm{Msr}^{+/+} / \mathrm{Cd}^{2} 6^{+/+}$-tp and $\mathrm{Msr}^{-/-} / \mathrm{Cd}_{3} 6^{-/-}$tp mice (Supplementary Figure $5 A-G$ ).

Cd68 expression was comparable in livers of both groups after HFC feeding (Figure 4D). Notably, the expression levels of the adenosine triphosphate (ATP)-binding cassette transporter $\mathrm{A} 1$ (Abca1) in liver revealed a significant decrease after 3 months on an HFC diet in the $\mathrm{Msr}^{-/-} / \mathrm{Cd} 36^{-/-}$-tp mice compared with $\mathrm{Msr}^{+/+} / \mathrm{Cd} 36^{+/+}$tp mice $(P=.02)$. The ATP-binding cassette transporter G1 (Abcg1) showed the same trend after long-term HFC feeding (Figure $4 D$ ). Moreover, there were already basal differences between $\mathrm{Msr}^{+/+} / \mathrm{Cd} 36^{+/+}-\mathrm{tp}$ and $\mathrm{Msr}^{-/-} /$ $C d 36^{-/-}$-tp mice for expression of Cd68, Abca1, and $A b c g 1$ 


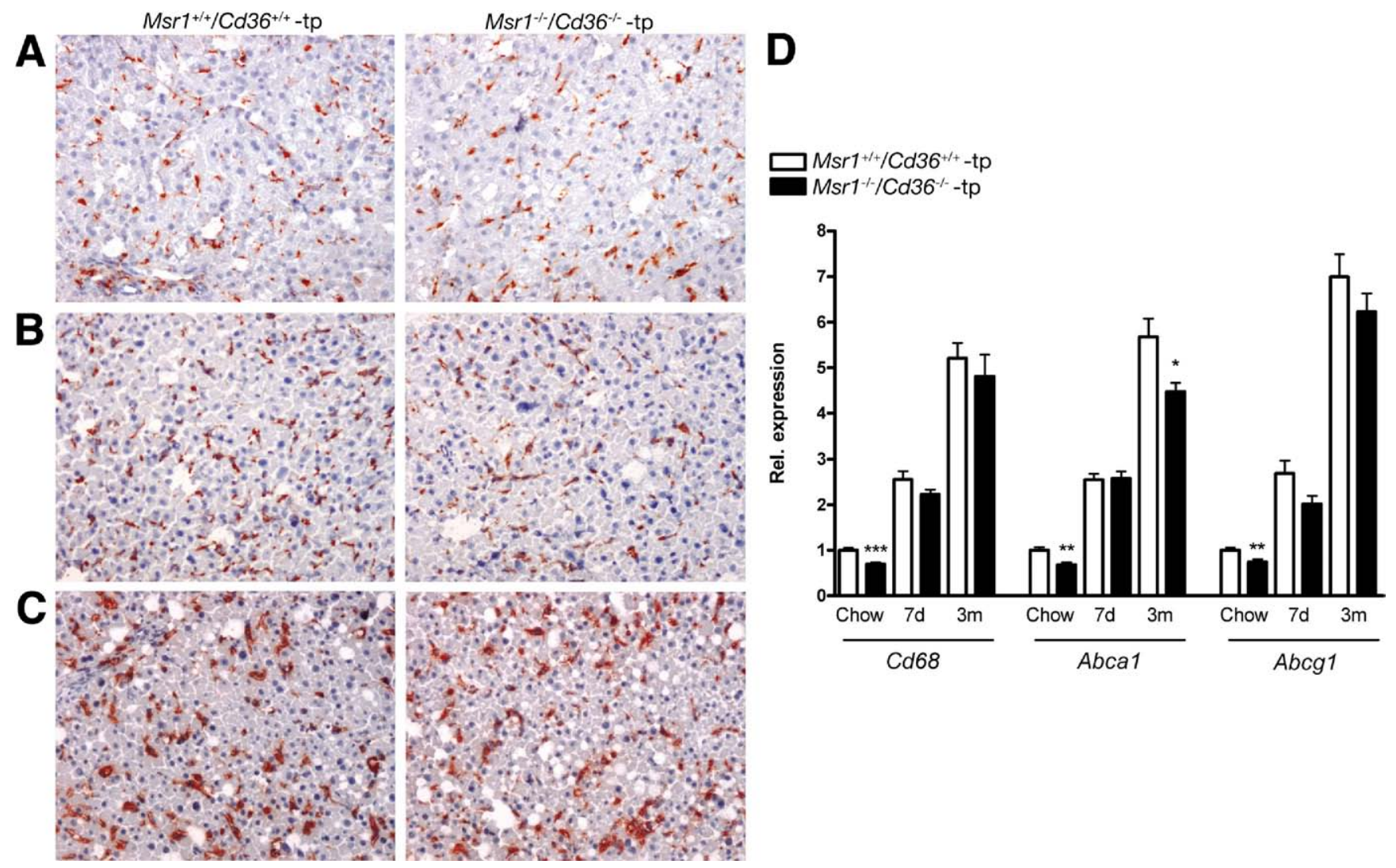

Figure 4. Foamy appearance of Kupffer cells. $(A-D)$ Representative pictures (original magnification, $200 \times)$ after chow, $(A) 7$ days $(B)$ and 3 months (C) of HFC diet with $\mathrm{Msr}^{+/+} / \mathrm{Cd} 36^{+/+}$-tp and $\mathrm{Msr}^{-/-} / \mathrm{Cd} 36^{-/-}$-tp mice, respectively. (D) Gene expression analysis of macrophage and Kupffer cell marker Cd68 and ATP-binding cassette transporters Abca1 and Abcg1. Data were set relative to the Msr1 ${ }^{+/+} / \mathrm{Cd} 36^{+/+}$-tp mice on chow diet. ${ }^{*}$ Significantly different from age-matched $M s r 1^{+/+} / C d 36^{+/+}$-tp group. ${ }^{*} P<.05$, ${ }^{* *} P<.01$, and ${ }^{* * *} P<.001$, respectively.

in total liver. Furthermore, gene expression analysis in whole liver revealed no compensation by other scavenger receptors (Supplementary Figure 6).

\section{Msr1-/-/Cd36-/- Transplanted Mice Show Less Lipid Oxidation Compared With Msr1 ${ }^{+/+} / \mathrm{Cd36}^{+/+}$Transplanted Mice}

To obtain an indirect measure of the degree of lipid oxidation, immunoglobulin (Ig) $\mathrm{M}$ and IgG autoantibodies against malondialdehyde (MDA)-LDL and copper-oxidized (Cu-Ox) LDL were measured in plasma of transplanted animals. For each time point, IgM autoantibody levels to MDA-LDL and Cu-OxLDL, which are thought to be to a large extent natural antibodies ${ }^{20}$ and to be inversely correlated with cardiovascular diseases, ${ }^{21,22}$ showed significant higher levels in $\mathrm{Msr}^{-/-} / \mathrm{Cd} 6^{-/-}$tp mice compared with $M s r 1^{+/+} / C d 36^{+/+}$-tp mice (MDA-IgM: $P=.001$ [chow], $P=.01[7$ days], $P<.0001$ [3 months]; Cu-Ox-IgM: $P=.006$ [chow], $P=.02[7$ days], $P=.0008$ [3 months]) (Figure $5 A$ and $B$ ). IgG autoantibody levels to MDA-LDL are significantly decreased in the $\mathrm{Msr}^{-/-} / \mathrm{Cd} 36^{-/-}$-tp mice after HFC feeding, indicating a less pronounced oxidative stress-mediated immune response $(P=.09$ [chow], $P=.006$ [7 days], $P=.03$ [3 months]) (Figure $5 \mathrm{C}$ ). The IgG levels against
$\mathrm{Cu}-\mathrm{OxLDL}$ were not significantly different after HFC diet but showed a basal difference between $\mathrm{Msr}^{+/+} / \mathrm{Cd} 36^{+/+}$tp and $\mathrm{Msr} 1^{-/-} / \mathrm{Cd} 36^{-/-}$-tp mice (Figure $5 D$ ). In line with the protective pattern of autoantibodies against oxLDL, 2 well-known oxysterols in plasma, 27- and 24S-hydroxycholesterol, were significantly lower after 3 months HFC diet in $\mathrm{Msr1}^{-/-} / \mathrm{Cd} 36^{-/-}$-tp mice compared with $\mathrm{Msr}^{+/+} /$ $C d 36^{+/+}$-tp mice $(P=.02, P=.008$, respectively), indicating less oxidation of cholesterol in these animals (Figure 5E). Similar to the decreased oxidation processes in these mice, the number of myeloperoxidase (MPO)positive cells, which can generate a variety of reactive oxygen species, was significantly lower in the livers of $\mathrm{Msr}^{-/-} / \mathrm{Cd} 36^{-/-}$-tp mice compared with $\mathrm{Msr}^{+/+} / \mathrm{Cd} 36^{+/+}$. tp mice $(P=.003$ [7 days], $P=.05$ [3 months]) (Figure $5 F)$.

\section{Discussion}

Our study shows for the first time the involvement of macrophage SRs in early and advanced stages of NASH. Reconstitution of $\mathrm{Ldlr}^{-/-}$mice with bone marrow from mice lacking both $M s r 1$ and Cd36 significantly reduced hepatic inflammation, lipid oxidation, and fibrosis without affecting steatosis. These novel observations sup- 


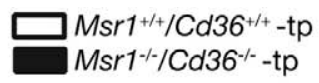

A

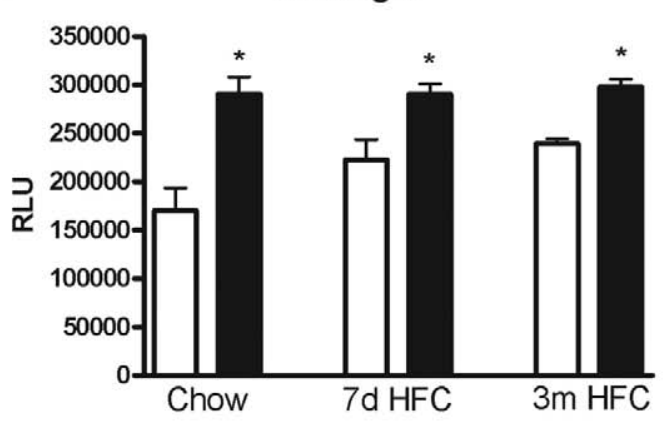

C
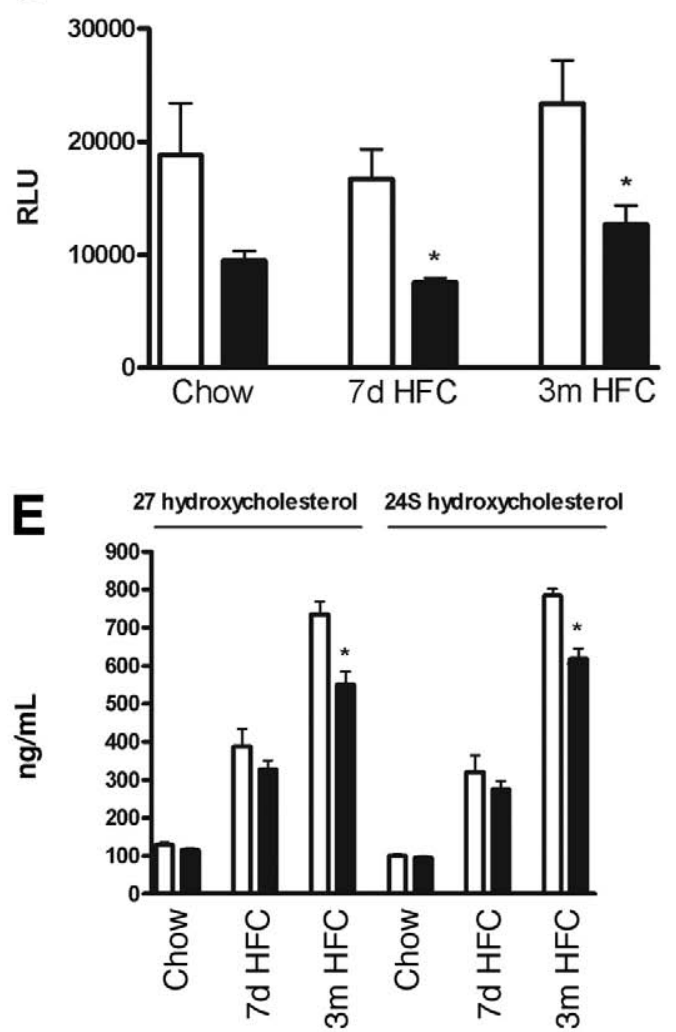

B

CuOx-IgM

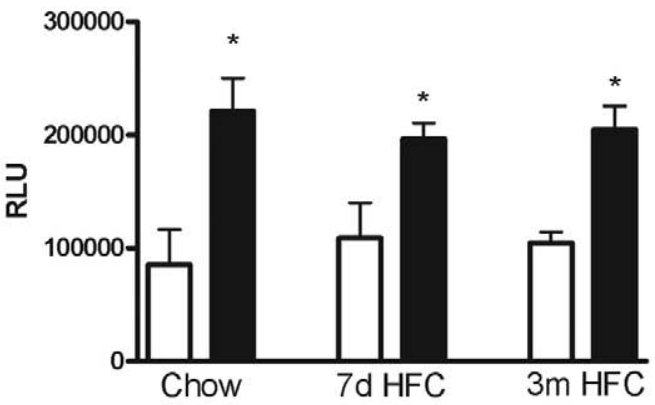

D

CuOx-lgG

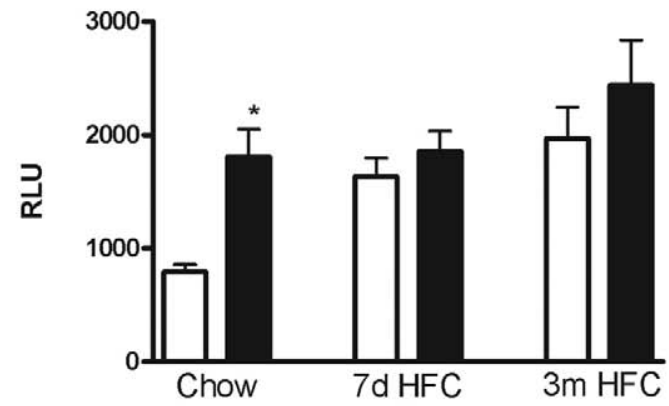

$\mathbf{F}$

MPO staining

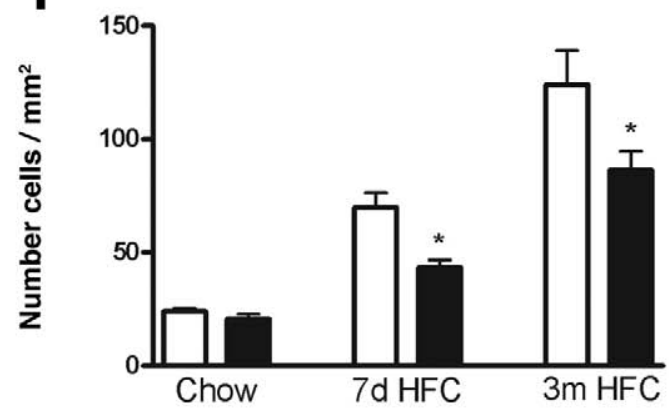

Figure 5. Parameters of oxidative damage. $(A-D) \lg$ and IgM autoantibody titers to MDA-LDL and CuOx-LDL in plasma, respectively. ( $E$ ) Oxysterols in plasma: 27- and 24S-hydroxycholesterol. ( $F$ ) Scoring of MPO-positive cells in liver sections. *Significantly different $(P<.05)$ from aged matched $\mathrm{Msr}^{+/+} / \mathrm{Cd} 36^{+/+}$-tp group.

port an analogy between mechanisms involved in the progression of liver inflammation and atherosclerosis.

\section{KCs Initiate Early Hepatic Inflammation by Scavenging Modified Lipoproteins}

Currently, the risk factors that drive hepatic inflammation during the progression to NASH are largely unknown. We have previously shown that hyperlipidemic mice are more sensitive to developing early, diet-induced NASH. ${ }^{8}$ In the current study, we demonstrate that the increased sensitivity of these mice to develop NASH is linked to expression of SR-A and CD36 on Kupffer cells.

The role of macrophage SRs CD36 and SR-A in atherogenesis has been intensively investigated. Uptake and internalization of modified LDL by SRs is believed to constitute one of the major pathways for foam cell formation in vivo. However, recent studies have revealed a wide spectrum of SR functions, including the activation of signal transduction pathways regulating inflammation, apoptotic cell clearance, chemoattraction, and an- 
giogenesis, which may also contribute to atherogenesis. ${ }^{23-25}$ The current paradigm suggests that SR-mediated uptake of oxidized lipoproteins by macrophages sets off a cascade of proinflammatory events leading to the initiation of the inflammatory response. In line with this view, we have observed that, upon targeted deletion of $C d 36$ and $M s r 1$ in macrophages, the hepatic inflammatory response was dramatically decreased in a mouse model of $\mathrm{NASH}$, as indicated by a decreased number of inflammatory cells and $\operatorname{Tnf}$. In line with this observation, deletion of both Msr1 and Cd36 in mice lacking Apoe was shown to reduce aortic expression levels of several chemokines and cytokines including $\operatorname{Tnf} .{ }^{19}$ Therefore, the effect that we have observed in the livers of $M s r 1^{-/-} / \mathrm{Cd}_{36^{-/-}}$tp mice is likely to be systemic and not restricted to the liver. Similarly, it was described that combined deletion of $C d 36$ and Msr1, and even deletion of Cd36 alone, resulted in decreased macrophage content, expression levels of serum proinflammatory cytokines, and aortic chemokine expression. ${ }^{18,19,26,27}$ Moreover, CD36 has been shown to facilitate TLR signaling in response to both oxLDL and diacylglyceride via TLR4/TLR6 and TLR2/6, respectively, and thereby trigger the innate host response. ${ }^{17,27-30}$ Thus, similar innate immune signaling pathways initiated by SRs may also be activated during steatosis, and these may promote inflammation associated with NASH. Notably, whereas most of the previous reports regarding the role of these SRs in inflammation were performed using the complete knock-out animals in an Apoe ${ }^{-/-}$background, our current study was performed in $\mathrm{Ldlr}^{-/-}$mice transplanted with bone marrow from mice lacking Msr1 and Cd36. Our approach has the advantage of being independent of the mixed genetic background of the mice, which may have confounded previous studies, and it has also allowed us to specifically examine the contribution of SRs meditated by macrophages on hepatic inflammation.

The decreased fibrosis and expression of fibrogenicrelated genes detected in the $\mathrm{Msr}^{-/-} / \mathrm{Cd} 36^{-/-}$-tp mice after 3 months of HFC diet were also associated with reduced levels of apoptosis. The effect on apoptosis may be attributed to the dramatic reduction in expression of Tnf, which is known to activate the expression of many proinflammatory cytokines and to induce apoptosis. ${ }^{31}$ There is considerable evidence contributing to the pathophysiologic concept that excessive apoptosis in the liver acts as a proinflammatory and profibrogenic trigger. ${ }^{32-34}$ The reduced level of apoptosis could therefore further contribute to the decreased development of fibrosis in the livers of the $\mathrm{Msr}^{-/-} / \mathrm{Cd} 36^{-/-}$-tp mice. In addition, Jaeschke ${ }^{35}$ and Lawson et $\mathrm{al}^{36}$ demonstrated that hepatocyte apoptosis is a potent stimulus for neutrophil infiltration and endotoxin-induced liver injury. These findings are in line with the finding that apoptosis correlates with enhanced myeloid cell infiltration and hepatic fibrosis in our models. Beside the reduced expression levels of inflammatory genes, levels of the anti-inflammatory nu- clear receptors $P$ par- $\alpha$ and $-\gamma$ were significantly higher in the livers of the $M s r 1^{-/-} / C d 36^{-/-}$-tp mice after 3 months. The recognition that, in addition to their anti-inflammatory response, PPARs are also associated with decreased liver fibrogenesis and tumorigenesis is relevant. ${ }^{37}$ Thus, the increase in hepatic expression of these nuclear receptors in the $\mathrm{Msr1}^{-/-} / \mathrm{Cd} 36^{-/-}$-tp mice may further contribute to the improvement of liver pathology in these mice.

\section{Inflammatory Response in Liver Is Attributed to Lipid Oxidation Rather Than to Foam Cell Formation}

Whereas our original hypothesis was that the inflammatory response in livers of hyperlipidemic mice would be related to foam cell formation, ${ }^{8}$ our data demonstrate a link between hepatic inflammation and LDL oxidation, rather than total lipid uptake. KCs lacking both $C d 36$ and $M s r 1$ were increased in size throughout the duration of the diet but were not significantly different from control macrophages. Although cholesterol content inside $\mathrm{KCs}$ was not different between $\mathrm{Msr}^{+/+}$/ $\mathrm{Cd} 36^{+/+}$-tp and $\mathrm{Msr1}^{-/-} / \mathrm{Cd} 36^{-/-}$-tp mice, gene expression analysis of $C d 68, A b c a 1$, and $A b c g 1$ in the liver showed already some basal differences. However, it is unlikely that these minor changes in gene expression are associated with a reduced efflux of cholesterol out of KCs via these ATP-binding cassettes.

MSR1 and CD36 have been shown to be critical contributors to modified lipoprotein uptake in macrophages in vitro. ${ }^{14}$ In addition, it has been shown that a specific CD36-dependent signaling pathway initiated by oxLDL is necessary for foam cell formation in vitro and in vivo. ${ }^{17}$ However, hyperlipidemic $\mathrm{Cd} 36^{-/-} / \mathrm{Apoe}^{-/-}$and $\mathrm{Msr}^{-/-}$, $A p o e^{-1-}$ mice develop abundant foamy macrophages in atherosclerotic plaques, indicating that lipid uptake by intimal macrophages can occur in the absence of CD36 and MSR $1{ }^{18}$ In line with these observations, it has also been shown that loss of both CD36 and MSR1 activity reduces atherosclerotic lesion complexity and inflammation in particular, without abrogating foam cell formation in $\mathrm{Apoe}^{-/-}$mice. ${ }^{19}$

It is important to note that there is still no clear evidence establishing that lipids that generate foam cells in vivo are derived from oxidized lipoproteins. In fact, there is considerable evidence that LDL-derived lipids can enter macrophages via SR-independent pathways. ${ }^{38} \mathrm{Na}$ tive LDL, which is present in much higher concentrations in plasma compared with modified/oxidized LDL, has been reported to be internalized via macropinocytosis of extracellular fluid. ${ }^{39}$ In addition, aggregated or enzymatically modified forms of LDL can also be internalized by macrophages. It is therefore possible that, whereas the total amounts of lipids in the hepatic macrophages from the $\mathrm{Msr}^{+/+} / \mathrm{Cd} 36^{+/+}$-tp and $\mathrm{Msr1} \mathrm{1}^{-/-} / \mathrm{Cd} 36^{-/-}$-tp mice are identical, the lipids may be qualitatively different or the 
mechanism of internalization may trigger more inflammatory pathways.

The reduced inflammatory response in the livers of the mice with targeted deletions of the 2 SRs was associated with diminished cholesterol oxidation and oxidative stress. This effect was also characterized by decreased hepatic MPO in $\mathrm{Msr1}^{-/-} / \mathrm{Cd} 36^{-/-}$-tp mice compared with $M s r 1^{+/+} / C d 36^{+/+}$-tp mice. MPO is secreted by neutrophils and monocytes that generate many oxidants, which can initiate the oxidation of LDL. Previously, it has been shown that CD36 is the major receptor for LDL modified by monocyte-generated reactive nitrogen species. ${ }^{40}$ These data suggest the existence of a defensive feedback mechanism to reduce levels of oxidation when CD36 expression is low. In line with the decreased levels of MPO in the liver, we observed significant differences in levels of IgM and IgG autoantibodies against modified LDL in the plasma of both transplanted groups. IgM autoantibodies to MDA-LDL and Cu-OxLDL are increased in $\mathrm{Msr}^{-{ }^{-1}}$ $C d 36^{-/-}$-tp mice, suggesting decreased consumption of these IgM, which have been suggested to be natural antibodies to a large part. ${ }^{20}$ In literature, it has been shown that IgM autoantibodies to MDA-LDL were inversely related with atherosclerosis. ${ }^{21,22}$ Interestingly, an IgG immune response induced by lipid peroxidation products correlates with hepatic inflammation during alcoholic steatohepatitis and the progression to advanced fibrosis during nonalcoholic steatohepatitis. ${ }^{41,42}$ Moreover, a number of studies have shown that the levels of IgG autoantibodies are correlated with increased risk for cardiovascular diseases. ${ }^{43,44}$ Surprisingly, the differences in levels of these autoantibodies between $\mathrm{Msr}^{+/+} / \mathrm{Cd} 36^{+/+}$tp and $M s r 1^{-/-} / C d 36^{-/-}$-tp mice were already observed at basal levels. The generation of natural antibodies is known to occur in the complete absence of external antigenic stimulation, and, therefore, it is not surprising that these antibodies are present already before the initiation of the HFC diet. Importantly, the basal differences between recipients of the 2 genotypes suggest that MSR1 and/or CD36 are critically involved in the generation of these antibodies. Thus, our data further add to the breadth of SR functions, in particular, the activation of additional immune responses with analogous specificity. Because this effect is likely to be systemic and not restricted to the liver, our observations regarding lipid oxidation are of general importance and also relevant to the field of atherosclerosis.

In conclusion, our study demonstrates that the SRs MSR1 and CD36 play an important role during early and advanced stages of NASH. Further studies are necessary to investigate the exact contribution of each of these receptors to dissect the molecular mechanisms involved in diet-induced NASH. Our data also establish the hyperlipidemic mice models as a tool to investigate the advanced stages of NASH in a physiologic context and provide a mechanism for the initiation and progression of the disease in these models. Finally, this study demonstrates for the first time an analogy between mechanisms for NASH and atherosclerosis. Thus, the focus on the liver as a crucial driver of inflammation in the metabolic syndrome is expected to provide alternative strategies leading to new therapies for preventing atherosclerosis. This study also provides new evidence for the close and complex link between lipid metabolism and inflammation, as manifested in cardiovascular diseases.

\section{Supplementary Material}

Note: To access the supplementary material accompanying this article, visit the online version of Gastroenterology at www.gastrojournal.org, and at doi: 10.1053/j.gastro.2010.02.051.

\section{References}

1. McCullough AJ. The clinical features, diagnosis and natural history of nonalcoholic fatty liver disease. Clin Liver Dis 2004;8: 521-533.

2. Parekh S, Anania FA. Abnormal lipid and glucose metabolism in obesity: implications for nonalcoholic fatty liver disease. Gastroenterology 2007;132:2191-2207.

3. Matsuzawa N, Takamura T, Kurita S, et al. Lipid-induced oxidative stress causes steatohepatitis in mice fed an atherogenic diet. Hepatology 2007;46:1392-1403.

4. Browning JD, Horton JD. Molecular mediators of hepatic steatosis and liver injury. J Clin Invest 2004;114:147-152.

5. Hotamisligil GS. Inflammation and metabolic disorders. Nature 2006;444:860-867.

6. Ruvolo PP. Intracellular signal transduction pathways activated by ceramide and its metabolites. Pharmacol Res 2003;47:383392.

7. Summers SA. Ceramides in insulin resistance and lipotoxicity. Prog Lipid Res 2006;45:42-72.

8. Wouters K, van Gorp PJ, Bieghs V, et al. Dietary cholesterol, rather than liver steatosis, leads to hepatic inflammation in hyperlipidemic mouse models of nonalcoholic steatohepatitis. Hepatology 2008;48:474-486.

9. Mari M, Caballero F, Colell A, et al. Mitochondrial free cholesterol loading sensitizes to TNF- and Fas-mediated steatohepatitis. Cell Metab 2006;4:185-198.

10. Vergnes L, Phan J, Strauss M, et al. Cholesterol and cholate components of an atherogenic diet induce distinct stages of hepatic inflammatory gene expression. J Biol Chem 2003;278: 42774-42784.

11. Yoshimatsu M, Terasaki $\mathrm{Y}$, Sakashita N, et al. Induction of macrophage scavenger receptor MARCO in nonalcoholic steatohepatitis indicates possible involvement of endotoxin in its pathogenic process. Int J Exp Pathol 2004;85:335-343.

12. Sano J, Shirakura S, Oda S, et al. Foam cells generated by a combination of hyperglycemia and hyperlipemia in rats. Pathol Int 2004;54:904-913.

13. Naito $M$, Kodama $T$, Matsumoto $A$, et al. Tissue distribution, intracellular localization, and in vitro expression of bovine macrophage scavenger receptors. Am J Pathol 1991;139:14111423.

14. Kunjathoor VV, Febbraio M, Podrez EA, et al. Scavenger receptors class $\mathrm{A}-\mathrm{I} / \mathrm{II}$ and $\mathrm{CD} 36$ are the principal receptors responsible for the uptake of modified low density lipoprotein leading to lipid loading in macrophages. J Biol Chem 2002;277:49982-49988. 
15. Suzuki H, Kurihara $Y$, Takeya $M$, et al. A role for macrophage scavenger receptors in atherosclerosis and susceptibility to infection. Nature 1997;386:292-296.

16. Moore KJ, Freeman MW. Scavenger receptors in atherosclerosis: beyond lipid uptake. Arterioscler Thromb Vasc Biol 2006;26: 1702-1711.

17. Rahaman So, Lennon DJ, Febbraio M, et al. A CD36-dependent signaling cascade is necessary for macrophage foam cell formation. Cell Metab 2006;4:211-221.

18. Moore KJ, Kunjathoor VV, Koehn SL, et al. Loss of receptormediated lipid uptake via scavenger receptor A or CD36 pathways does not ameliorate atherosclerosis in hyperlipidemic mice. J Clin Invest 2005;115:2192-2201.

19. Manning-Tobin JJ, Moore KJ, Seimon TA, et al. Loss of SR-A and CD36 activity reduces atherosclerotic lesion complexity without abrogating foam cell formation in hyperlipidemic mice. Arterioscler Thromb Vasc Biol 2008;29:19-26.

20. Chou MY, Fogelstrand L, Hartvigsen K, et al. Oxidation-specific epitopes are dominant targets of innate natural antibodies in mice and humans. J Clin Invest 2009;119:1335-1349.

21. Karvonen J, Paivansalo M, Kesaniemi YA, et al. Immunoglobulin $\mathrm{M}$ type of autoantibodies to oxidized low-density lipoprotein has an inverse relation to carotid artery atherosclerosis. Circulation 2003;108:2107-2112.

22. Horkko S, Bird DA, Miller E, et al. Monoclonal autoantibodies specific for oxidized phospholipids or oxidized phospholipid-protein adducts inhibit macrophage uptake of oxidized low-density lipoproteins. J Clin Invest 1999;103:117-128.

23. Platt $N$, Suzuki $H$, Kurihara $Y$, et al. Role for the class $A$ macrophage scavenger receptor in the phagocytosis of apoptotic thymocytes in vitro. Proc Natl Acad Sci U S A 1996;93:1245612460.

24. Febbraio M, Hajjar DP, Silverstein RL. CD36: a class B scavenger receptor involved in angiogenesis, atherosclerosis, inflammation, and lipid metabolism. J Clin Invest 2001;108:785-791.

25. Cotena A, Gordon S, Platt N. The class A macrophage scavenger receptor attenuates CXC chemokine production and the early infiltration of neutrophils in sterile peritonitis. J Immunol 2004; 173:6427-6432.

26. Kuchibhotla S, Vanegas D, Kennedy DJ, et al. Absence of CD36 protects against atherosclerosis in ApoE knock-out mice with no additional protection provided by absence of scavenger receptor A I/II. Cardiovasc Res 2008;78:185-196.

27. Stewart CR, Stuart LM, Wilkinson K, et al. CD36 ligands promote sterile inflammation through assembly of a Toll-like receptor 4 and 6 heterodimer. Nat Immunol 2010;11:155-161.

28. Hoebe K, Georgel P, Rutschmann S, et al. CD36 is a sensor of diacylglycerides. Nature 2005;433:523-527.

29. Triantafilou M, Gamper FG, Lepper PM, et al. Lipopolysaccharides from atherosclerosis-associated bacteria antagonize TLR4, induce formation of TLR2/1/CD36 complexes in lipid rafts and trigger TLR2-induced inflammatory responses in human vascular endothelial cells. Cell Microbiol 2007;9:2030-2039.

30. Stuart LM, Deng J, Silver JM, et al. Response to Staphylococcus aureus requires CD36-mediated phagocytosis triggered by the COOH-terminal cytoplasmic domain. J Cell Biol 2005;170:477485.

31. Rath PC, Aggarwal BB. TNF-induced signaling in apoptosis. J Clin Immunol 1999;19:350-364.

32. Canbay A, Kip SN, Kahraman A, et al. Apoptosis and fibrosis in non-alcoholic fatty liver disease. Turk J Gastroenterol 2005;16: $1-6$.

33. Maher JJ, Scott MK, Saito JM, et al. Adenovirus-mediated expression of cytokine-induced neutrophil chemoattractant in rat liver induces a neutrophilic hepatitis. Hepatology 1997;25:624-630.
34. Lauber K, Bohn E, Krober SM, et al. Apoptotic cells induce migration of phagocytes via caspase-3-mediated release of a lipid attraction signal. Cell 2003;113:717-730.

35. Jaeschke H. Neutrophil-mediated tissue injury in alcoholic hepatitis. Alcohol 2002;27:23-27.

36. Lawson JA, Fisher MA, Simmons CA, et al. Parenchymal cell apoptosis as a signal for sinusoidal sequestration and transendothelial migration of neutrophils in murine models of endotoxin and Fas-antibody-induced liver injury. Hepatology 1998;28:761767.

37. Gervois P, Vu-Dac N, Kleemann R, et al. Negative regulation of human fibrinogen gene expression by peroxisome proliferatoractivated receptor alpha agonists via inhibition of CCAAT box/ enhancer-binding protein beta. J Biol Chem 2001;276:3347133477.

38. Kruth HS, Jones NL, Huang W, et al. Macropinocytosis is the endocytic pathway that mediates macrophage foam cell formation with native low-density lipoprotein. J Biol Chem 2005;280: 2352-2360

39. Kruth HS, Huang W, Ishii I, et al. Macrophage foam cell formation with native low-density lipoprotein. J Biol Chem 2002;277: 34573-34580.

40. Podrez EA, Schmitt D, Hoff HF, et al. Myeloperoxidase-generated reactive nitrogen species convert LDL into an atherogenic form in vitro. J Clin Invest 1999;103:1547-1560.

41. Occhino GIA, Hietala J, Sutti S, et al. ESBRA 2007. Abstracts of the 11th Congress of the European Society for Biomedical Research on Alcoholism, 23-26 September, Berlin, Germany. Alcohol Suppl 2007;42:i1-66.

42. Albano E, Mottaran E, Vidali M, et al. Immune response towards lipid peroxidation products as a predictor of progression of nonalcoholic fatty liver disease to advanced fibrosis. Gut 2005;54: 987-993.

43. Tsimikas S, Brilakis ES, Lennon RJ, et al. Relationship of IgG and IgM autoantibodies to oxidized low-density lipoprotein with coronary artery disease and cardiovascular events. J Lipid Res 2007; 48:425-433.

44. Hulthe J, Wiklund O, Hurt-Camejo E, et al. Antibodies to oxidized $\mathrm{LDL}$ in relation to carotid atherosclerosis, cell adhesion molecules, and phospholipase A(2). Arterioscler Thromb Vasc Biol 2001;21:269-274.

Received May 15, 2009. Accepted February 23, 2010.

\section{Reprint requests}

Address requests for reprints to: Ronit Shiri-Sverdlov, PhD, Department of Molecular Genetics, Maastricht University UNS50/11, P.0. Box 616, 6200 MD Maastricht, The Netherlands. e-mail: r.sverdlov@gen.unimaas.nl; fax: (31) 43-388-4574.

\section{Acknowledgments}

The authors thank Inge van der Made, Pieter Goossens, Monique Vergouwe, and Tim Hendrikx for their excellent technical support; Patrick Lindsey for his statistical advice; and Sander Rensen for providing the MPO antibody and staining protocol.

\section{Conflicts of interest}

The authors disclose no conflicts.

\section{Funding}

Veni: 916.76 .070 (2006/00496/MW); Maag Lever Darm Stichting (MLDS) (WO 08-16); Dutch Heart Fondation (NHS) (2002B18); Vidi: 016.066.329. 


\section{Supplementary Materials and Methods}

\section{Mice, Diet, and Bone Marrow Transplantation}

Mice were housed under standard conditions and given free access to food and water. Experiments were performed according to Dutch laws, approved by the Committee for Animal Welfare of Maastricht University. One week before transplantation, 10-week-old female, low-density lipoprotein (LDL) receptor-deficient $\left(\mathrm{Ldlr}^{-/-}\right)$ mice were put into filter top cages and received acidified water supplemented with neomycin $(100 \mathrm{mg} / \mathrm{L}$; N1142; Sigma-Aldrich, St. Louis, MO) and polymyxin B sulphate (60,000 U/L; 21850-029; Life Technologies Cooperation, Carlsbad, CA). One day before transplantation, mice were subjected to a full-body irradiation with a lethal dose of $10 \mathrm{~Gy}$. The bone marrow of 5 female wild-type mice and 5 female $\mathrm{Msr}^{-/-} / \mathrm{Cd} 36^{-/-}$littermates was collected and pooled. Each irradiated $L d l r^{-/-}$mouse received $10^{7}$ bone marrow cells by injection into the tail vein. After a recovery period of 9 weeks, the mice were given a high-fat, high-cholesterol (HFC) diet for 7 days ( $\mathrm{n}=8$ in $\mathrm{Msr}^{+/+}$/ $\mathrm{Cd} 36^{+/+}$and $\mathrm{n}=8$ in $\mathrm{Msr}^{-/-} / \mathrm{Cd} 36^{-/-}$-tranplanted [tp] mice) and 3 months ( $\mathrm{n}=7$ in $\mathrm{Msr}^{+/+} / \mathrm{Cd} 36^{+/+}$-tp group, $\mathrm{n}=8$ in $\mathrm{Msr}^{-/-} / \mathrm{Cd} 36^{-/-}$-tp group), containing $21 \%$ butter and $0.2 \%$ cholesterol (diet 1635; Scientific Animal Food and Engineering, Villemoisson-sur-Orge, France). Chow fed mice that were killed after 9 weeks recovery were used as control group ( $\mathrm{n}=7$ in both $\mathrm{Msr}^{+/+} / \mathrm{Cd}_{3} 6^{+/+_{-}}$ tp and $\mathrm{Msr}^{-/-} / \mathrm{Cd} 36^{-/-}$-tp mice). Blood from the tail vein was collected before the dietary period, after 7 days on the HFC diet in the short-term group, and after 3 months in the long-term group on the day of death after a 4-hour fast period. The mice were then killed by cervical dislocation. Tissues were isolated and snap frozen in liquid nitrogen and stored at $-80^{\circ} \mathrm{C}$ or fixed in $4 \%$ formaldehyde/phosphate-buffered saline.

\section{Plasma Lipid Analysis}

Both plasma and liver lipid levels were measured with enzymatic color tests (cholesterol CHOD-PAP; 1489232; Roche, Basel, Switzerland; serum triglyceride (TG) determination kit, TR0100; Sigma-Aldrich; NEFAC, ACS-ACOD, 999-75406; Wako Chemicals, Neuss, Germany) according to the manufacturer's protocols on a Benchmark 550 Micro-plate Reader (170-6750XTU; BioRad, Hercules, CA).

\section{Liver Lipid Analysis}

Approximately $50 \mathrm{mg}$ of frozen liver tissue was homogenized for 30 seconds at $5000 \mathrm{rpm}$ in a closed tube with $1.0-\mathrm{mm}$ glass beads and $1.0 \mathrm{~mL}$ SET buffer (sucrose $250 \mathrm{mmol} / \mathrm{L}$, EDTA $2 \mathrm{mmol} / \mathrm{L}$, and Tris $10 \mathrm{mmol} / \mathrm{L}$ ). Complete cell destruction was done by 2 freeze-thaw cycles and 3 times passing through a 27-gauge syringe needle and a final freeze-thaw cycle. Protein content was measured with the bicinchoninic acid (BCA) method
(23225; Pierce, Rockford, IL). Cholesterol, triglycerides (TG), and free fatty acids (FFA) were measured as described above. Protocols were followed according to the manufacturers' instructions.

\section{Liver Histology}

Frozen liver sections $(7 \mu \mathrm{m})$ were fixed in acetone and subsequently blocked for endogenous peroxidase by incubation with $0.25 \%$ of $0.03 \% \mathrm{H}_{2} \mathrm{O}_{2}$ for 5 minutes. Primary antibodies used were against infiltrated macrophages and neutrophils (rat-anti-mouse Mac-1 [M1/70]) and $\mathrm{T}$ cells (rat-anti-mouse CD3) (both generous gifts from Prof Kraal, Free University, Amsterdam, The Netherlands), neutrophils (rat-anti-mouse Ly6-C, clone NIMPR14) (generous gift from Prof Heeringa, Groningen, The Netherlands), Kupffer cells (KCs) (rat-anti-mouse CD68, clone FA11) (generous gift from Prof Gordon, Oxford, UK), and apoptosis (rabbit-anti-mouse cleaved caspase 3) (9661Lg; Cell Signalling, Danvers, MA). 3-Amino-9-ethylcarbazole (AEC) (A85SK-4200.S1; Bio-connect, Huissen, The Netherlands) was applied as color substrate and hematoxylin (4085.9002, Klinipath, Duiven, The Netherlands) for nuclear counterstaining. Sections were enclosed with Faramount aqueous mounting medium (S302580; DAKO, Glostrup, Denmark). For the lipid stainings, the neutral lipid marker oil red o (ORO; O0625; Sigma-Aldrich) and the fluorescent free cholesterol marker Filipin (F9765, Sigma-Aldrich) were used. The filipin staining was quantified by scoring all filipinpositive KCs between 0 and 3, where score 0 indicates not positive, and score 3 indicates extremely positive for cholesterol content inside the KCs.

Paraffin-embedded liver sections $(4 \mu \mathrm{m})$ were stained with Hematoxylin-Eosin (HE; Hematoxilin, 4085.9002; Klinipath, Duiven, The Netherlands; and Eosin, E4382; Sigma-Aldrich), Sirius red (Direct Red 80, 43665; SigmaAldrich), and rabbit-anti-mouse myeloperoxidase (A0398; DAKO). Pictures were taken with a Nikon digital camera DMX1200 and ACT-1 v2.63 software (Nikon Instruments Europe, Amstelveen, The Netherlands). Immune cells were counted in 6 microscopical views (original magnification, $200 \times$ ) and were noted as cells/square millimeter.

\section{RNA Isolation and Quantitative Polymerase Chain Reaction}

Total RNA was isolated from approximately 25 mg of mouse liver tissues as described previously. ${ }^{1}$ All applications were performed according to the manufacturers' protocols. Total RNA (500 ng) from each individual mouse was converted into first-strand complementary DNA (cDNA) with the iScript cDNA synthesis kit (170-8891; Bio-Rad, Hercules, CA) according to the manufacturer's instructions. The changes in gene expression of inflammatory markers were determined by quantitative polymerase chain reaction (PCR) (qPCR) on an SDS 
7900HT by using PowerSybr Green mastermix (4329001 and 4368708; both Applied Biosystems, Foster City, CA) and $10 \mathrm{ng}$ of cDNA. For each gene, a standard curve was generated with a serial dilution of a liver cDNA pool. To standardize for the amount of cDNA, Cyclophillin A (Ppia) was used as the reference gene. Primer sets for the selected genes were developed with Primer Express version 2.0 (Applied Biosystems) using default settings. Primer sequences are given in Supplementary Table 1. Data from qPCR were analyzed according to the relative standard curve method.

\section{Chimerism Determination by $q P C R$}

For the determination of the chimerism in the transplanted mice, we have made use of the knowledge that donor bone marrow has an $L d l r^{W T}$ origin, whereas recipient bone marrow an $\mathrm{Ldlr}^{-/-}$origin. Genomic DNA was isolated using the NucleoSpin Blood QuickPure DNA isolation kit (740569; Macherey Nagel, Düren, Germany).

A standard curve was generated by mixing DNA from $L d l r^{-/-}$and $L d l r^{W T}$ bone marrow cells at different ratios. Chimerism was determined by quantifying the amount of $\mathrm{Ldlr}^{-/-}$DNA in samples from $70 \mu \mathrm{L}$ peripheral blood. To standardize for the amount of input DNA, the nonrelevant $p 50$ gene was quantified. Samples were assayed in duplicate on a 7900HT real-time PCR system by using 25 ng DNA, PowerSybr Green mastermix (4329001 and 4368708; both Applied Biosystems), according to the manufacturer's instructions. $\mathrm{Ldlr}^{-/-}$specific primers are forward $5^{\prime}$-GCTGCAACTCATCCATATGCA-3' and reverse 5'-GGAGTTGTTGACCTCGACTCTAGAG-3. p50-specific primers are forward 5'-ACCTGGGAATACTTCATGTGACTAA-3' and reverse 5'-ACACCAGAAGTCCAGGATTATAGC-3'.

A standard curve was generated by plotting the mean threshold cycle (Ct) $\Delta \mathrm{Ct}\left(\mathrm{Ct} p 50-\mathrm{Ct} \mathrm{ddlr}^{-/-}\right.$) against the logarithm of the percentage $\mathrm{Ldlr}^{-/-}$and calculation of a regression line. Chimerism was calculated from the percentage of $\mathrm{Ldlr}^{-/-}$DNA in the blood samples (representing the remaining recipient bone marrow), determined by applying the mean $\Delta \mathrm{Ct}$ of the sample to the standard curve.

\section{Measuring Aminotranferases}

The level of aminotransferases, alanine aminotransferase and aspartate aminotransferase, in plasma of each individual mouse was measured by using the Reflotron system and the test strips for alanine aminotransferase and aspartate aminotransferase measurments (Roche Diagnostics, Almere, The Netherlands), according to the manufacturer's instructions. Shortly, for each aminotransferase, $32 \mu \mathrm{L}$ plasma was loaded on the appropriate test strip and inserted into the machine. After 2 minutes, the results were shown on the display.

\section{Measuring Autoantibody Titers Against Modified LDL}

Specific antibody titers against modified LDL in plasma were determined as described elsewhere. ${ }^{2,3}$ Plasma was serially diluted and antibody binding measured by chemiluminescent enzyme-linked immunosorbent assay. A titer was defined as the reciprocal of the maximal dilution at which binding of the secondary antibody was twice as high as the background binding.

\section{Measuring Oxysterols}

The oxysterols 24S- and 27-hydroxycholesterol were measured after extraction from plasma as their trimethylsilyl ethers by highly specific and sensitive gas chromatography-mass spectrometry as described previously. 4,5 Deuterium labeled 24S- and 27-hydroxycholesterol were used as internal standards as an isotope dilution method.

\section{Statistical Analysis}

Data were statistically analyzed by performing 2-tailed, nonpaired, $t$ tests using GraphPad Prism, version 4.03 for Windows (GraphPad Software, San Diego, CA; www.graphpad.com) for comparing $\mathrm{Msr}^{+/+} / \mathrm{Cd} 36^{+/+}$-tp and $\mathrm{Msr} \mathrm{r}^{-/-} / \mathrm{Cd} 36^{-/-}$-tp mice for each diet group. Oneway analysis of variance test was used for comparing the different time points of high-fat feeding within the same acceptor mice. Data were expressed as the mean \pm standard error of mean and considered significant at $P<.05$ $\left({ }^{*} P<.05,{ }^{*} P<.01\right.$, and ${ }^{*}{ }^{*} P<.001$, respectively).

\section{References}

1. Shiri-Sverdlov R, Wouters K, van Gorp PJ, et al. Early diet-induced non-alcoholic steatohepatitis in APOE2 knock-in mice and its prevention by fibrates. J Hepatol 2006;44:732-741.

2. Horkko S, Bird DA, Miller E, et al. Monoclonal autoantibodies specific for oxidized phospholipids or oxidized phospholipid-protein adducts inhibit macrophage uptake of oxidized low-density lipoproteins. J Clin Invest 1999;103:117-128.

3. Binder CJ, Hartvigsen K, Chang MK, et al. IL-5 links adaptive and natural immunity specific for epitopes of oxidized LDL and protects from atherosclerosis. J Clin Invest 2004;114:427-437.

4. Lutjohann D, Stroick M, Bertsch T, et al. High doses of simvastatin, pravastatin, and cholesterol reduce brain cholesterol synthesis in guinea pigs. Steroids 2004;69:431-438.

5. Thelen KM, Rentsch KM, Gutteck U, et al. Brain cholesterol synthesis in mice is affected by high dose of simvastatin but not of pravastatin. J Pharmacol Exp Ther 2006;316:1146-1152. 
Supplementary Table 1. Primer Sequences for Quantitative PCR

\begin{tabular}{|c|c|c|}
\hline Gene & Primer forward & Primer reverse \\
\hline TNF & CATCTTCTCAAAATTCGAGTGACAA & TGGGAGTAGACAAGGTACAACCC \\
\hline IL-6 & GCTACCAAACTGGATATAATCAGGAAA & CTTGTTATCTTTTAAGTTGTTCTTCATGTACTC \\
\hline TLR-4 & TATCCAGGTGTGAAATTGAAACAATT & GGGTTTCCTGTCAGTATCAAGTTTG \\
\hline TLR-2 & AATTGCATCACCGGTCAGAAA & GTTTGCTGAAGAGGACTGTTATGG \\
\hline PPAR- $\alpha$ & TTCCCTGTTTGTGGCTGCTAT & TGCAACTTCTCAATGTAGCCTATGTT \\
\hline PPAR- $\gamma$ & TCGCTGATGCACTGCCTATG & GAGAGGTCCACAGAGCTGATT \\
\hline CD68 & TGACCTGCTCTCTCTAAGGCTACA & TCACGGTTGCAAGAGAAACATG \\
\hline ABCA1 & CCCAGAGCAAAAAGCGACTC & GGTCATCATCACTTTGGTCCTTG \\
\hline ABCG1 & TCGGACGCTGTGCGTTTT & CCCACAAATGTCGCAACCT \\
\hline CoL1A1 & AACCCTGCCCGCACATG & CAGACGGCTGAGTAGGGAACA \\
\hline MMP-13 & ACAAAGATTATCCCCGCCTCATA & CACAATGCGATTACTCCAGATACTG \\
\hline TIMP-1 & CGCCTAAGGAACGGAAATTTG & GATAGATAAACAGGGAAACACTGT \\
\hline TGF- $\beta$ & AGCGCTCACTGCTCTTGTGA & GTCGCCCCGACGTTTG \\
\hline CD36 & GCCAAGCTATTGCGACATGA & AAAAGAATCTCAATGTCCGAGACTTT \\
\hline SR-A & CATACAGAAACACTGCATGTCAGAGT & TTCTGCTGATACTTTGTACACACGTT \\
\hline LOX1 & TCCCCGTTCTGGATTGGAT & TTGCCTGATGAATATAGCTGTAAAGAAA \\
\hline SR-B1 & TTCTTCACTACGCGCAGTATGTG & САСTCCAAAACAAAAAGCATTTCTC \\
\hline SR-CL & TAGACGGGTCACCTGTTGATTACA & ATTGATTTCATCACACTGGAAGTCAT \\
\hline SR-EC & GACGACTCCTTCTCTTCTGATCCT & TGGGCCATAGGGACCATCT \\
\hline PSOX & TGCAGTCCAAAAGCGTGTGT & GTGGTGAAAACTCTTCCCATGAC \\
\hline PPIA & TTCСTCСTTTCACAGAATTATTCCA & CCGCCAGTGCCATTATGG \\
\hline
\end{tabular}

